\title{
Chemical acceleration of a neutral granulated blast-furnace slag activated by sodium carbonate
}

Maxim Kovtun*, Elsabe P. Kearsley, Julia Shekhovtsova

Department of Civil Engineering, University of Pretoria, Pretoria, 0002 South Africa max.kovtun@up.ac.za (M Kovtun)

elsabe.kearsley@up.ac.za (EP Kearsley)

j.shekhovtsova@gmail.com (J Shekhovtsova)

*Corresponding author at: Department of Civil Engineering, University of Pretoria, Pretoria, 0002 South Africa. Tel.: +27 12420 6953. E-mail address: max.kovtun@up.ac.za (M

Kovtun)

\begin{abstract}
This paper presents results of a study on chemical acceleration of a neutral granulated blastfurnace slag activated using sodium carbonate. As strength development of alkali-activated slag cements containing neutral GBFS and sodium carbonate as activator at room temperature is known to be slow, three accelerators were investigated: sodium hydroxide, ordinary Portland cement and a combination of silica fume and slaked lime. In all cements, the main hydration product is $\mathrm{C}-(\mathrm{A})-\mathrm{S}-\mathrm{H}$, but its structure varies between tobermorite and riversideite depending on the accelerator used. Calcite and gaylussite are present in all systems and they were formed due to either cation exchange reaction between the slag and the activator, or carbonation. With accelerators, compressive strength up to $15 \mathrm{MPa}$ can be achieved within 24 hours in comparison to $2.5 \mathrm{MPa}$ after 48 hours for a mix without an accelerator.
\end{abstract}

Keywords: Alkali-Activated Cement; Acceleration; Admixture; Compressive Strength; Hydration Products. 


\section{Introduction}

Alkali-activated slag (AAS) concretes are considered as a possible alternative to ordinary Portland cement (OPC) concretes. There are four main activators usually used to activate slags, namely sodium silicates, sodium hydroxide, sodium sulphate, and sodium carbonate.

Sodium silicates provide the highest strength [1-4] and chemical resistance [5], but their usage is associated with high shrinkage $[1,4,6,7]$, challenging rheology of fresh concrete mix, relatively high cost of the concretes and high amounts of associated $\mathrm{CO}_{2}$ emissions [8]. Sodium silicates and their combinations with sodium hydroxide provide fast setting, resulting in limited time for casting and finishing of AAS concrete. [7].

Sodium hydroxide is another commonly used abundant alkali, but its usage for slag activation provides relatively low strength $[2,3]$, high porosity and coarse pore structure $[9,10]$. Sodium hydroxide solution has the highest $\mathrm{pH}$ value amongst the activators. It is therefore highly corrosive, and safety during production of AAS concretes becomes an issue.

Sodium sulphate is the cheapest amongst the four activators used for AAS concretes but it provides the lowest strength, especially at an early age, and poor resistance to frost and carbonation [2] 
Sodium carbonate provides high strength, good durability, long setting times and the lowest shrinkage $[1,4,11,12]$. Sodium carbonate solution is much less corrosive than sodium silicate/hydroxide, making for safer work environments. However, a major shortcoming of sodium carbonate as activator, is the slow strength development of AAS concretes containing acid or neutral slags hardened at ambient temperature $[13,14]$.

Recent research on AAS concretes has mainly focused on sodium silicate and sodium hydroxide activators and their combinations $[10,15,16]$. Thus, literature on AAS concretes containing sodium carbonate as the main activator is limited, especially on acceleration of strength development of AAS concretes containing acid or neutral slags hardened at ambient temperature.

The aim of this research is to add knowledge on AAS concretes containing sodium carbonate and neutral GBFS. Three accelerating admixtures were used in this study, and their effect on hydration products and strength development was investigated. 


\section{Experimental setup}

\subsection{Materials}

A granulated blast-furnace slag was used to produce AAS concretes. The chemical composition of the slag is presented in Table 1. The GBFS was a neutral slag with a basicity coefficient $\left(\mathrm{K}_{\mathrm{b}}=(\mathrm{CaO}+\mathrm{MgO}) /\left(\mathrm{Al}_{2} \mathrm{O}_{3}+\mathrm{SiO}_{2}\right)\right)$ of 0.92 based on the chemical composition as indicated in Table 1. X-ray diffraction analysis shows that the slag is a glassy phase with minor inclusions of gehlenite. The particle size range of slag, determined by laser granulomentry, was $0.4-152 \mu \mathrm{m}$, with a mean $\left(\mathrm{d}_{50}\right)$ of $16.8 \mu \mathrm{m}$ and $10 \%$ of particles finer than $1.8 \mu \mathrm{m}$.

\section{Table 1}

Chemical composition and physical characteristics of used materials.

characteristics

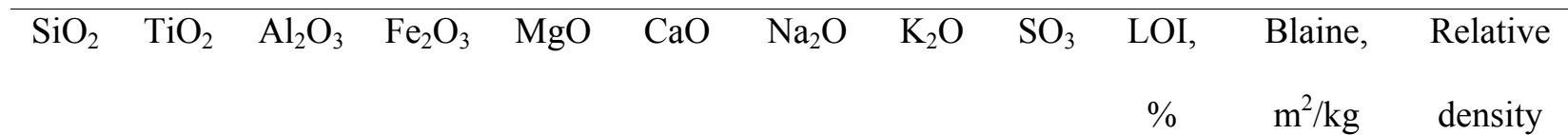

$\begin{array}{lcccccccccccc}\text { Slag } & 34.87 & 0.72 & 14.38 & 0.89 & 8.03 & 37.05 & <0.01 & 0.72 & 1.96 & 0.16 & 425 & 2.90 \\ \text { Cem I 52.5N } & 22.30 & 0.50 & 4.98 & 3.35 & 1.92 & 61.50 & 0.21 & 0.26 & 2.92 & 1.77 & 480 & 3.17 \\ \text { Silica fume } & 84.00 & 0.03 & 0.75 & 1.96 & 1.08 & 2.22 & 0.17 & 3.43 & 0.09 & 5.56 & \text { n.a. } & 2.30 \\ \text { Slaked lime } & 4.01 & 0.03 & 0.37 & 0.36 & 1.67 & 67.8 & 0.00 & 0.08 & 0.11 & 25.0 & 1060 & 2.33 \\ \end{array}$


Commercially available sodium carbonate $(99,0 \%$ purity) was used to prepare the activator solutions. Tap and distilled water was used to prepare alkaline solutions for AAS concretes and pastes respectively.

Sodium hydroxide flakes (98.5\% purity), OPC CEM I 52.5N, combination of silica fume and slaked lime were used as admixtures to promote early strength development of AAS concretes at room temperature. The chemical composition and physical characteristics of the materials are shown in Table 1. The particle size distribution of CEM I 52.5N was $0.4-93$ $\mu \mathrm{m}$, with a mean $\left(\mathrm{d}_{50}\right)$ of $16.4 \mu \mathrm{m}$ and $10 \%$ of particles finer than $3.5 \mu \mathrm{m}$.

Crushed dolomite stone and dolomite sand were used as aggregates. The relative density of the aggregates was 2.86 . The maximum size of coarse aggregate was $9.5 \mathrm{~mm}$. The sand had a fineness modulus of 3.86 with $9 \%$ particles smaller than $75 \mu \mathrm{m}$.

\subsection{Mix designs}

Based on results of previous research indicating that it provided good durability [15] and compressive strength [16], all AAS concrete mixes (Table 2) contained $500 \mathrm{~kg} / \mathrm{m}^{3}$ of binder $($ slag + OPC + silica fume + slaked lime $)$. 
Table 2

AAS concrete mix designs and properties

\begin{tabular}{|c|c|c|c|c|c|c|c|c|c|c|}
\hline \multirow{2}{*}{$\begin{array}{l}\text { Mix } \\
\text { code }\end{array}$} & \multicolumn{7}{|c|}{ Components, $\mathrm{kg} / \mathrm{m}^{3}$} & \multirow{3}{*}{$\begin{array}{l}\text { Initial } \\
\text { set, min }\end{array}$} & \multirow{3}{*}{$\begin{array}{c}\text { Final } \\
\text { set, min }\end{array}$} & \multirow{3}{*}{$\begin{array}{c}\text { Slump: } \\
\text { mm/Vebe: } \\
\text { sec }\end{array}$} \\
\hline & Slag & Cem I $52.5 \mathrm{~N}$ & Silica fume & Slaked lime & Stone & Sand & Activator $^{\mathrm{a})}$ & & & \\
\hline & & & & & & & & & & \\
\hline $\mathrm{SC}$ & 500 & & & & 1200 & 650 & $3.5 / 0$ & 455 & $>600$ & $10 / 11$ \\
\hline $\mathrm{SH} 20$ & 500 & & & & 1200 & 650 & $2.8 / 0.9$ & 125 & 195 & $10 / 11$ \\
\hline SH50 & 500 & & & & 1200 & 650 & $1.8 / 2.3$ & 155 & 330 & $5 / 12$ \\
\hline SH100 & 500 & & & & 1200 & 650 & $0 / 4.7$ & 90 & 175 & $5 / 12$ \\
\hline OPC3 & 485 & 15 & & & 1203 & 651 & $4.6 / 0$ & 55 & 120 & $0 / 12$ \\
\hline OPC4 & 480 & 20 & & & 1203 & 651 & $4.6 / 0$ & 40 & 105 & $0 / 12$ \\
\hline OPC5 & 475 & 25 & & & 1203 & 651 & $4.7 / 0$ & 40 & 90 & $0 / 15$ \\
\hline SFSL & 470 & & 15 & 15 & 1196 & 649 & $4.5 / 0$ & 45 & 165 & $0 / 18$ \\
\hline
\end{tabular}

${ }^{\text {a) }}$ Sodium carbonate/sodium hydroxide in $\mathrm{Na}_{2} \mathrm{O}$ wt.\% of slag.

The coarse to fine aggregate weight ratio of $65: 35$ and water to binder ratio of 0.35 were kept constant in all mixes.

\subsection{Sample synthesis and tests procedures}

Setting times were measured according to BS EN 196-3:2005 [17] in a temperature and relative humidity controlled room at $25^{\circ} \mathrm{C}$ and $97 \pm 2 \%$. The water/binder ratio was kept 
constant at $0.26[18]$ and the moulds filled with AAS cement paste were not submerged into water between measurements to avoid alkali leaching.

The concrete preparation procedure consisted of mixing dry materials in a pan mixer, the addition of aqueous activator solution, and a further one and a half minute of mixing. Workability (slump, Vebe test) was tested following the standard procedure of BS EN 12350:2009 [19], before placing the fresh concrete mix in $100 \mathrm{~mm}$ plastic cube moulds. Compaction was done by vibration. Cast samples were cured at $25^{\circ} \mathrm{C}$ and $>90 \%$ humidity for the first 24 hours. Samples of the control mix without accelerating admixtures (SC, Table 2) were cured for 48 hours as they could not be de-moulded at 24 hours due to slow strength development. After de-moulding, all samples were stored in a room with constant conditions: $25{ }^{\circ} \mathrm{C}$ and $55 \%$ relative humidity. Concrete samples were tested for compressive strength according to the standard procedure BS EN 12390-3 [20] at 1, 28, and 91 days.

Analysis of pore solution chemistry was done on pore liquid expressed from $100 \mathrm{ml}$ paste samples. AAS paste mixes were obtained by excluding aggregates from corresponding concrete mix designs (Table 2).The paste samples were cast into plastic bottles and cured under controlled conditions at $20 \pm 1{ }^{\circ} \mathrm{C}$. The expression of pore solution from hardened AAS pastes was performed using a device similar to one described by Barneyback and Diamond [21]. Elemental composition of the pore solutions was studied by a Spectro-Acros Inductively-Coupled Plasma Optical Emission Spectroscopy (ICP-OES) instrument. 
AAS pastes were prepared for mineralogical and microstructural characterization with X-ray Diffractometry (XRD), Attenuated Total Reflectance Fourier Transform Infrared Spectroscopy (ATR-FTIR), Scanning Electron Microscopy (SEM), Electron Backscattered Scanning Electron Microscopy (BSE) and Energy Dispersive Spectroscopy (EDS). Paste samples were cured at $25{ }^{\circ} \mathrm{C}$ and $>90 \%$ humidity for the first 24 hours and at $25{ }^{\circ} \mathrm{C}$ and $55 \%$ relative humidity afterwards.

XRD analysis was done at 1 and 28 days. Paste samples were crushed into small pieces with a maximum size of $5 \mathrm{~mm}$ and submerged into ethanol to prevent further hydration. Crushed samples were then dried at $50{ }^{\circ} \mathrm{C}$ for 12 hours and milled in a tungsten carbide mill. The powdered samples were analysed using a PANalytical X'Pert Pro powder diffractometer in $\theta-$ $\theta$ configuration with an $\mathrm{X}^{\prime}$ Celerator detector and variable divergence and receiving slits with Fe filtered Co-K $\alpha$ radiation $(\lambda=1.789 \AA)$. The specimens were collected in the $2 \theta$ range $5-90^{\circ}$ with a scanning rate of $17^{\circ} / \mathrm{sec}$ and a step size of $0.017^{\circ} 2 \theta$. The phases were identified using X'Pert Highscore plus software.

Samples of pastes for SEM investigation were crushed at 1 and 28 days, washed with ethanol, and placed into a desiccator. Freshly fractured surfaces were coated with carbon and studied using a Zeiss Ultra Plus SEM at an accelerating voltage of $1 \mathrm{kV}$.

BSE/EDS studies were carried out on 1-day pastes. Samples were submerged into ethanol for 24 hours to remove the capillary water, dried in a desiccator before epoxy resin impregnation 
in vacuum. Samples were ground and polished using diamond pads $(66,28.8$ and $16 \mu \mathrm{m})$ and diamond suspensions $(9,3,1$ and $0.25 \mu \mathrm{m})$. Polished sections were coated with a single carbon layer to provide a layer of minimal thickness which would be undetectable during EDS scanning. A JEOL JSM 5800 scanning electron microscope $(20.0 \mathrm{kV})$ fitted with a solid-state BSE detector and a Thermo Scientific NSS7 energy dispersive X-ray analyser (EDS), was used for the study.

Samples for ATR-FTIR analysis were prepared as for XRD. Infrared spectra were recorded using a Golden Gate diamond ATR cell (Bruker), which fits in the macro sample compartment of a Vertex 70v spectrometer (Bruker Optics). The contact area between the sample and the diamond ATR crystal is $2 \mathrm{~mm}$ in diameter. Spectra were recorded with 32 acquisitions at $4 \mathrm{~cm}^{-1}$ resolution over a spectral range of $4000-600 \mathrm{~cm}^{-1}$.

\section{Results and discussion}

\subsection{Setting times and workability}

Setting times and workability of AAS cements and concretes are presented in Table 2. In general, the addition of accelerating admixtures shortens setting times and decrease workability. 


\subsection{Compressive strength}

As mentioned before, three admixtures to accelerate hydration of AAS concretes containing neutral GBFS and sodium carbonate at room temperatures were investigated. The first accelerating admixture used in this study, was sodium hydroxide $[13,22]$. Sodium hydroxide increases the $\mathrm{pH}$ of alkaline solutions, which facilitates dissolution of the slag glass structure and promotes hydration. Two mixes, $\mathrm{SH} 20$ and $\mathrm{SH} 50$, were chosen to compare with the control mix SC (Table 2). For comparative purposes, a mix containing only sodium hydroxide as activator was cast (SH100, Table 2). Strength development of the mixes can be seen in Fig. 1.

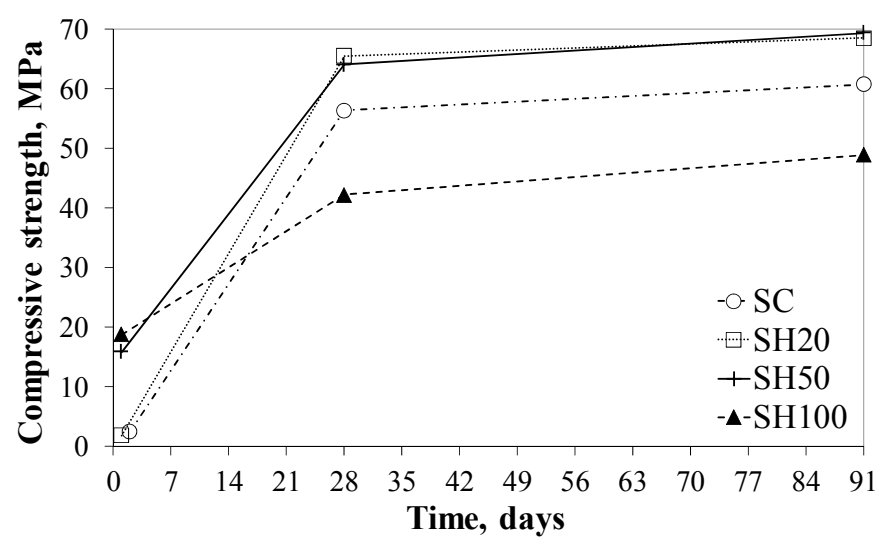

Fig. 1. Strength development of AAS concretes accelerated with admixture of sodium hydroxide. 
Replacement of sodium carbonate with 20 wt.\% sodium hydroxide (SH20, Fig. 1) gives noticeable acceleration of strength development at 24 hours. SH20 samples yielded average strength of $1.8 \mathrm{MPa}$ after 24 hours while samples of the control mix could not be demoulded and were tested after 48 hours. The level of acceleration however is not significant and could not be used in industrial applications. The mix accelerated with $50 \mathrm{wt} . \%$ sodium hydroxide shows significant increase in an early strength (SH50, Fig. 1). The strength is comparable to strength of the mix activated with only sodium hydroxide. It is significant that $50 \mathrm{wt} \%$. replacement of sodium carbonate with sodium hydroxide does not impair the strength in comparison to the control mix at later stages of hydration. Activation with only sodium hydroxide (SH100, Fig. 1) shows the lowest strength in the long term, in comparison to other mixes, which confirms the results of other researchers [2]. SH50 mix shows the best result in terms of strength kinetics of AAS concretes. The result confirms the findings made by Collins and Sanjayan [13] who showed that combinations of sodium hydroxide to sodium carbonate of 5:4 and 3:4 gave the best strength development.

The second admixture used for acceleration of AAS concrete hydration at room temperature, was OPC $[14,22,23]$. An addition of alite and belite minerals accelerates hydration of neutral and acid slags activated with sodium carbonate solution [23]. Compressive strength results for the AAS concrete accelerated with 3, 4 and 5\% OPC (Table 2) are presented in Fig. 2. The strength development of the AAS concretes at room temperature confirms the findings made by Glukhovsky et al [23]. 


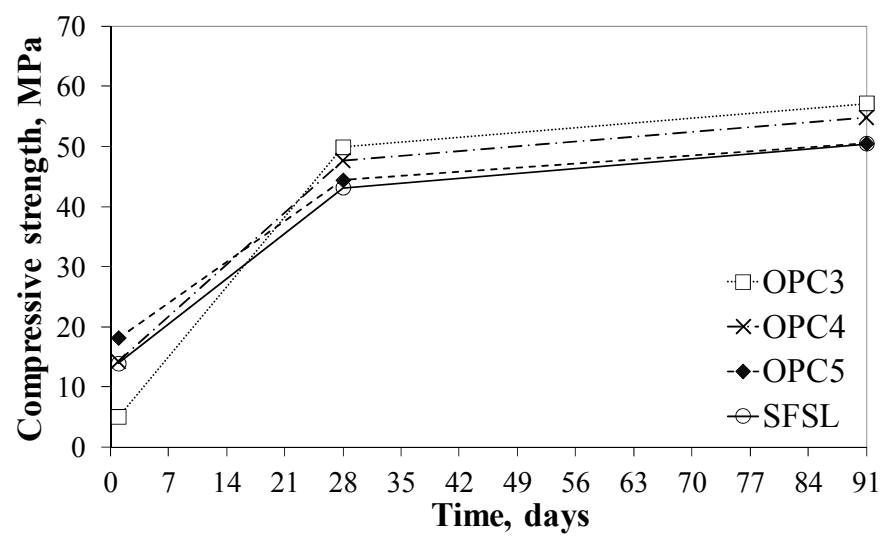

Fig. 2. Strength development of AAS concretes accelerated with OPC and combination of silica fume and slaked lime.

It can be seen that 1-day strength increases with increasing OPC replacement from 3 to 5 wt.\%, but 28 day strength is reduced. At all levels of replacement of slag with OPC, strength of AAS concretes is reduced in comparison to the control mix at 28 and 91 days (SC, Fig. 1). The reduction in strength at 28 and 91 days can be caused by the gypsum contained in OPC $[2,14]$. Wang et al [2] emphasised that gypsum neutralises the alkaline component and produces expansive non-binding mirabilite $\left(\mathrm{Na}_{2} \mathrm{SO}_{4} \cdot 10 \mathrm{H}_{2} \mathrm{O}\right)$ and thus has a detrimental effect on strength. OPC was used in this study because it is available on the market, while cement clinker, which would be preferable as accelerating admixture [14], is not accessible to small producers. In terms of early and long-term strength, 4 wt.\% of OPC gives the best results amongst the mixes accelerated with OPC (Fig. 2). 
The third accelerating admixture was a combination of silica fume and slaked lime. This method of acceleration was driven by the hypothesis that when OPC is added to promote hydration, slag hydration is accelerated by $\mathrm{C}-\mathrm{S}-\mathrm{H}$ formed during rapid cement hydration. The rapid cement hydration is caused by an alkaline solution of sodium carbonate [24]. The $\mathrm{C}-\mathrm{S}-\mathrm{H}$ act as crystallization centres (substrate) which promotes slag hydration and formation of new portions of C-S-H [25-27]. Combinations of silica fume and slaked lime were used by Douglas and Brandstetr [28] to promote early strength development of AAS concretes, but different percentages of the admixtures and different activators were used in comparison to the present study. Douglas and Brandstetr [28] used the sodium silicate solutions as activators providing sufficient amounts of readily available reactive silica. The nature of the activator in this study is different; and the AAS concrete did not contain high levels of available silica for reaction in the system at early stages of hydration, due to the relatively low $\mathrm{pH}$ of the sodium carbonate activator. The low $\mathrm{pH}$ causes slow breakage of the strong $\mathrm{Si}-\mathrm{O}$ bonds in the slag glassy phase [2]. The addition of silica fume with slaked lime introduces sources of silica and calcium required for $\mathrm{C}-\mathrm{S}-\mathrm{H}$ formation and eventually accelerates hydration of AAS concretes containing sodium carbonate. Slaked lime instead of unslaked lime was chosen to prevent possible pseudo-flash setting which could be the result of a local rise in temperature caused by the exothermal reaction between unslaked lime and water. Unslaked lime would also increase water demand of the binder due to the immediate and intensive reaction with water. The strength development of concrete mixes accelerated with the combination of silica fume and slaked lime (SFSL, Table 2) is shown in Fig. 2. Accelerating effect of the admixture is similar to that of OPC. At 1 day, strength of SFSL mix is equal to the strength of the mix accelerated with 4 wt.\% OPC, but long-term strength decreases and matches the strength of OPC5 mix. Strength results show that a combination of silica fume and slaked lime efficiently 
accelerates AAS concrete containing neutral GBFS and sodium carbonate at an early stage, but long-term strength decreases in comparison to the control mix (SC, Fig. 1).

The strength development of AAS concretes is governed by the interactions between solid and liquid components; that is dissolution rates, saturation/chemical equilibrium of the pore solution, precipitation or hydration rates and microstructural evolution [29]. The following sections are thus focused on these various aspects of AAS concrete hydration; and changes caused by the accelerating admixtures. AAS pastes were used in further studies.

\subsection{Pore solution chemistry}

The composition of the pore solution in the AAS pastes was analysed after 1 day of hydration. The most prominent difference in chemistry of the pore solutions is $\mathrm{Si}$ concentration (Table 3). SC and SH20 pastes which had the lowest strength at 1 day (Fig. 1), have very high Si concentration. When the concentration of ionic species reach the product of solubility of different solid compounds, they precipitate, generating the microstructure of the AAS pastes [30]. Puertas et al [30] reported that the concentration of Si in the pore solution drastically reduced from 3 to 24 hours of hydration due to precipitation of $\mathrm{C}-\mathrm{S}-\mathrm{H}$ gel. Thus, the pore solution of the pastes with high Si concentration had not reached complete saturation

at 1 day; and the high $\mathrm{Si}$ concentration is associated with the fresh pastes before or during very early stages of C-S-H formation [31]. SEM study of AAS pastes confirms (see SEM section below) that the low strength of the base paste is caused by lack of hydration products. 
The concentration of $\mathrm{Mg}$ in all pore solutions (Table 3) is relatively high in comparison to previously published results [30,31]; and it reduces in the accelerated AAS pastes indicating possible precipitation of hydrotalcite-type phase (see XRD and EDS sections below). The concentration of $\mathrm{Al}$ is also high in all pore solutions, except the control paste, indicating that $\mathrm{Al} / \mathrm{Si}$ ratios are considerably higher than that recorded by other researches [29-31]. The low Al concentration in the pore solution of the base paste additionally confirms a slow rate of dissolution of slag particles. The relatively high $\mathrm{Mg}$ and $\mathrm{Al}$ concentrations (Table 3 ) can be caused by the nature of activator used in this study.

\section{Table 3}

Concentration of ions in pore solution of AAS pastes at 1 day $(\mathrm{mg} / \mathrm{l})$.

\begin{tabular}{lcccc}
\hline Paste & $\mathrm{Ca}$ & $\mathrm{Al}$ & $\mathrm{Si}$ & $\mathrm{Mg}$ \\
\hline $\mathrm{SC}$ & 11.2 & 139 & $>2212$ & 2.2 \\
SH20 & 12.6 & 448 & $>2338$ & 1.5 \\
SH50 & 5.7 & 810 & 761 & 1.2 \\
SH100 & 6.0 & 804 & 706 & 1.2 \\
OPC3 & 10.8 & 560 & 363 & 1.1 \\
OPC4 & 8.7 & 626 & 361 & 1.1 \\
OPC5 & 8.8 & 575 & 416 & 1.1 \\
SFSL & 11.0 & 629 & 364 & 1.0 \\
\hline
\end{tabular}




\section{4. $X R D$}

The diffractograms of the anhydrous slag and 1-day AAS pastes are presented in Fig. 3. Tobermorite $\left(\mathrm{Ca}_{2.25} \mathrm{Si}_{3} \mathrm{O}_{7.5}(\mathrm{OH})_{1.5} \mathrm{H}_{2} \mathrm{O}\right.$, Powder Diffraction File (PDF) \# 01-083-1520) was identified in all AAS pastes except the paste accelerated with the combination of silica fume and slaked lime. In the X-ray diffractogram of the later paste, the peaks attributed to poorly crystalline riversideite $\left(\mathrm{Ca}_{5} \mathrm{Si}_{6} \mathrm{O}_{16}(\mathrm{OH})_{2}, \mathrm{PDF} \#\right.$ 00-029-0329) were found. Both types of $\mathrm{C}-$ S-H most certainly have some degree of Al substitution [10,32]. It is important to note that despite the high Si concentration in the pore solution of the control paste, indicating early stage $\mathrm{C}-\mathrm{S}-\mathrm{H}$ precipitation, and the very small amount of hydration products observed by BSE at 1 day (see SEM section below) tobermorite-type C-S-H could be detected by XRD (Fig. 3). This can be explained by elevated crystallinity of C-S-H gel in AAS systems $[29,33]$. For all pastes, two types of carbonates, calcite $\left(\mathrm{CaCO}_{3}, \mathrm{PDF} \#\right.$ 01-072-1937) and gaylussite $\left(\mathrm{Na}_{2} \mathrm{Ca}\left(\mathrm{CO}_{3}\right)_{2}\left(\mathrm{H}_{2} \mathrm{O}\right)_{5}\right.$, PDF\# 01-074-1235), were identified, along with gehlenite $\left(\mathrm{Ca}_{2} \mathrm{Al}(\mathrm{AlSi}) \mathrm{O}_{7}, \mathrm{PDF} \#\right.$ 01-089-5917) residual from the source slag. Gaylussite was previously found in alkali-activated binders by other researches [34,35] while calcite can be attributed to atmospheric carbonation and cation exchange reaction between slag and sodium carbonate. A small amount of vaterite $\left(\mathrm{CaCO}_{3}, \mathrm{PDF} \#\right.$ 01-074-1867) was found in the AAS paste accelerated with the combination of silica fume and slaked lime. 


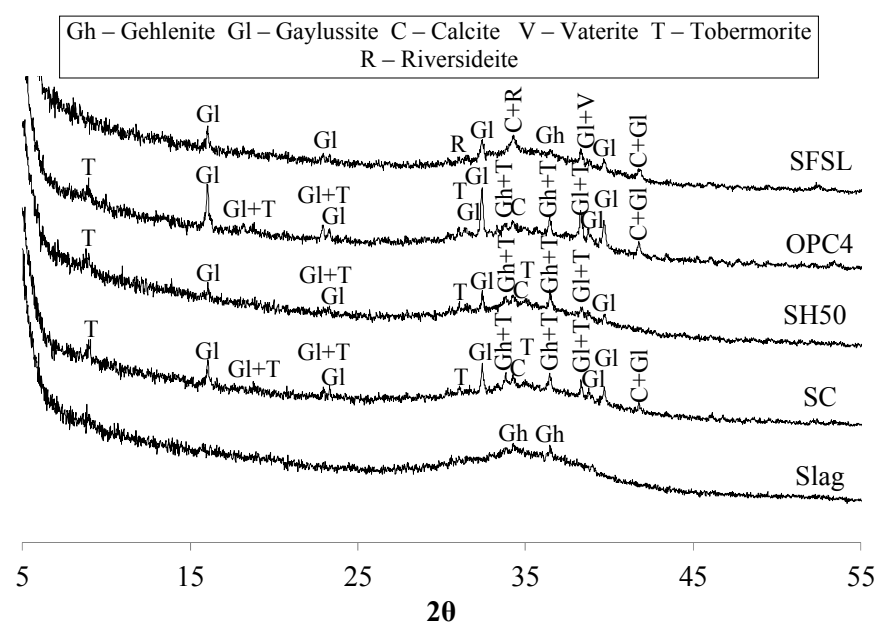

Fig. 3. X-ray diffractograms of raw slag and AAS pastes at 1 day.

Fig. 4 presents the diffractograms of 28-days AAS pastes. Riversideite was identified in pastes accelerated with OPC and the combination of silica fume and slaked lime. The intensity of the peaks significantly increases from day 1 , indicating that more of riversideite was formed. The intensity can also be affected by increased level of polymerization of C-S$\mathrm{H}$ gel in the pastes confirmed by the shift of the peak around $960 \mathrm{~cm}^{-1}$ to higher wave numbers (see ART-FTIR section below), but the peak on ART-FTIR spectra also has increased intensity at 28 days which confirms the increase in amount of the $\mathrm{C}-\mathrm{S}-\mathrm{H}$ formed. The increase in intensity of the XRD peaks serves as a good indicator of riversideite formation in the accelerated pastes (OPC4 and SFSL, Fig. 4), identification of which would be difficult due to overlapping with the calcite peak at around $34^{\circ} 2 \theta$. The control paste shows minor changes in the overlapping peak, which indicates an absence of riversideite (SC, Fig. 4). Calcite and gaylussite remain in all AAS pastes but the intensity of their peaks decreases in the accelerated pastes. Gehlenite is identified in all pastes. The formation of hydrotalcite 
$\left(\mathrm{Mg}_{0.667} \mathrm{Al}_{0.333}(\mathrm{OH})_{2}\left(\mathrm{CO}_{3}\right)_{0.167}\left(\mathrm{H}_{2} \mathrm{O}\right)_{0.5}\right.$, PDF\# 01-089-0460) is observed in the pastes accelerated with sodium hydroxide and the combination of silica fume and slaked lime.

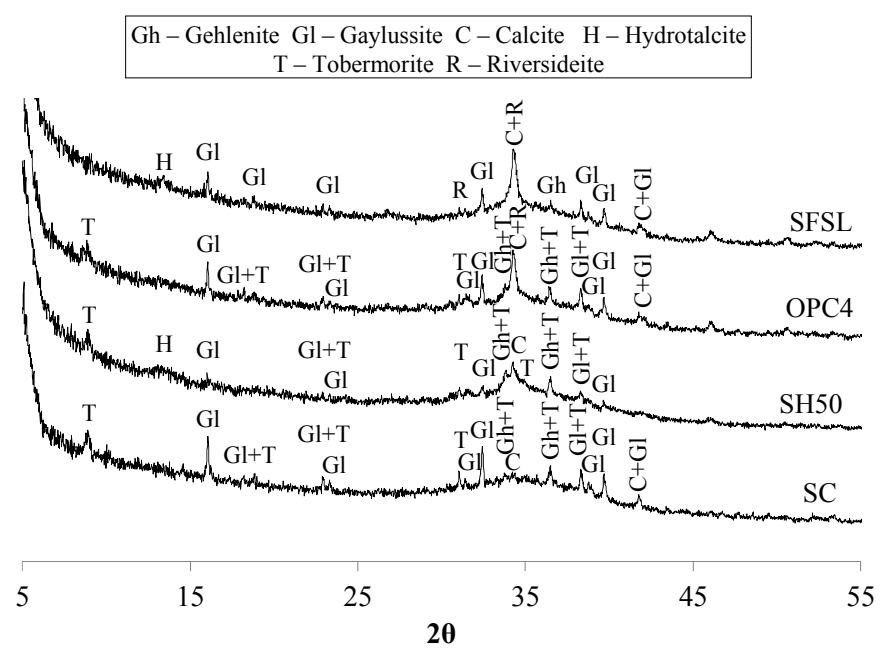

Fig. 4. X-ray diffractograms of AAS pastes at 28 days.

\subsection{ATR-FTIR}

FTIR spectra of the samples of AAS pastes are presented in Fig. 5 and 6. Bands typical for carbonate phases can be seen at $870-873 \mathrm{~cm}^{-1}$ (the out-of-plane bending of the $\mathrm{C}-\mathrm{O}$ bond) and $1418-1491 \mathrm{~cm}^{-1}$ (the asymmetric stretching of $\mathrm{C}-\mathrm{O}$ bond) [36]. These bands are related to the presence of carbonates which were identified by XRD analysis (Fig. 3,4). AAS paste accelerated with the combination of silica fume and slaked lime has a prominent band at 1491 $\mathrm{cm}^{-1}$ at day 1 of hardening (Fig. 5). This band can indicate the presence of vaterite [36] which was also confirmed by XRD analysis of the paste at day 1 (Fig. 3). The bands related to water 
can be observed at $1650-1690 \mathrm{~cm}^{-1}$ (bending vibrations in $\mathrm{H}_{2} \mathrm{O}$ molecules) for all the pastes. These bands do not appear in anhydrous slag (Fig. 5) and indicate the presence of crystalline or adsorbed molecules of water on the surfaces of reaction products. The bands become more prominent at 28 days (Fig. 6) which shows the progress of hydration and development of more products like $\mathrm{C}-\mathrm{S}-\mathrm{H}$ gel. The most prominent difference between the AAS pastes at 1 day (Fig. 5) is in the region of the stretching vibrations of the $\mathrm{T}-\mathrm{O}-\mathrm{T}$ bonds (T: tetrahedral $\mathrm{Si}$ or $\mathrm{Al}$ ) at $800-1200 \mathrm{~cm}^{-1}$. A well-developed band at $957 \mathrm{~cm}^{-1}$ and a shoulder at $1117 \mathrm{~cm}^{-1}$ can be seen in the spectra of the paste accelerated with a combination of silica fume and slaked lime. The band at $957 \mathrm{~cm}^{-1}$ is assigned to the $\mathrm{Si}-\mathrm{O}$ stretching vibrations generated by $\mathrm{Q}^{2}$ tetrahedra that comprise $\mathrm{C}-\mathrm{S}-\mathrm{H}$ and more specifically $\mathrm{C}-(\mathrm{A})-\mathrm{S}-\mathrm{H}$ gel [37-39]. The shoulder at $1117 \mathrm{~cm}^{-1}$ can be associated with the formation of a silicon-rich gel with some sodium in its composition and a higher degree of polymerization than the $\mathrm{C}-(\mathrm{A})-\mathrm{S}-\mathrm{H}$ gel $[38,40]$. The shoulder does not appear at 28 days (Fig. 6) indicating that the silicon-rich gel reacts, as hydration time increases, forming additional $\mathrm{C}-(\mathrm{A})-\mathrm{S}-\mathrm{H}$ gel. At 28 days, the main difference between the control and accelerated pastes is the appearance of a band around $960 \mathrm{~cm}^{-1}$. It is much more developed in the case of accelerated pastes due to more $\mathrm{C}-(\mathrm{A})-\mathrm{S}-\mathrm{H}$ gel formation. In the case of pastes accelerated with OPC and the combination of silica fume and slaked lime, the band also shifts towards higher wave numbers of $963 \mathrm{~cm}^{-1}$. The shift indicates a higher degree of polymerization, a decrease in the $\mathrm{Ca} / \mathrm{Si}$ and an increase in the $\mathrm{Si} / \mathrm{Al}$ ratio in the $\mathrm{C}-(\mathrm{A})-\mathrm{S}-\mathrm{H}$ gel structure $[37,38,41]$. 


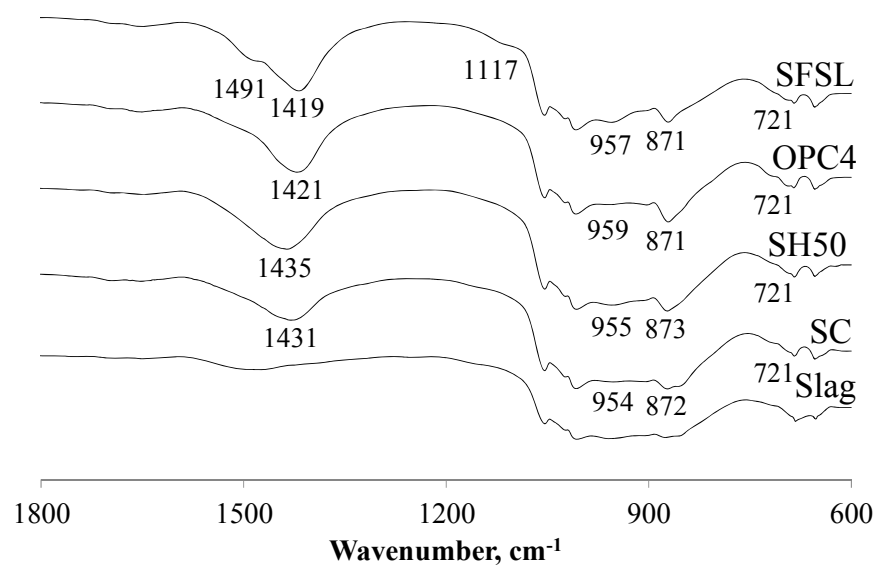

Fig. 5. FTIR spectra of raw slag and AAS pastes at 1 day.

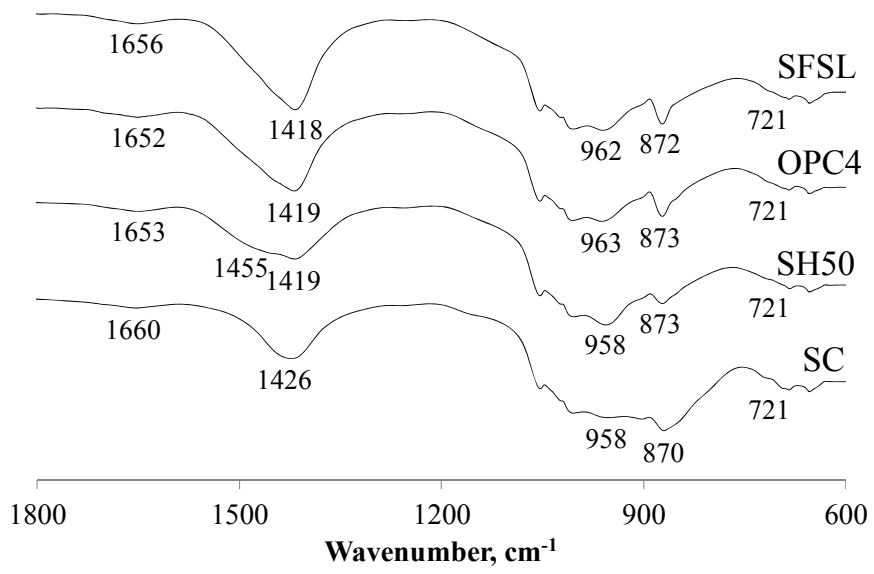

Fig. 6. FTIR spectra of AAS pastes at 28 days. 


\subsection{SEM}

Scanning electron microscope images of the AAS pastes microstructure are presented in Fig. 7 to Fig 9. Normally the microstructure of AAS paste is dominated by the relatively fast "through solution" precipitation of a gel-like $\mathrm{C}-\mathrm{S}-\mathrm{H}$ matrix in the pore space; and the internal space between the slag grains is readily completely filled with $\mathrm{C}-\mathrm{S}-\mathrm{H}$ gel after 24 hours when stronger activators (sodium silicate, sodium hydroxide) are used [29]. It can be seen that the control paste activated with sodium carbonate shows little hydration at early age (Fig. 7A). The structure of the paste is very friable (Fig. 7A, left) and porous (Fig. 7A, right). Many slag particles look untouched with sharp edges and no clear signs of reaction products on the particle surfaces (Fig. 7A, left). Very little hydration products can be seen in the BSE image either (Fig. 7A, right) showing low level of reaction with the activator. The SEM study supports the results on the pore solution chemistry of AAS pastes (Table 3), indicating that the pore solution of the control paste did not reach complete saturation at 24 hours, caused by slow dissolution of slag particles (Fig. 7A); and the formation of $\mathrm{C}-\mathrm{S}-\mathrm{H}$ gel was at early stage. All accelerated pastes produced noticeable amounts of hydration products after 1 day of curing (Fig. 7B-D). Cracks can be seen throughout the structure of all the accelerated AAS pastes. They are most probably caused by conditioning of the samples as AAS concretes are more sensitive to drying than OPC concrete [32]. 

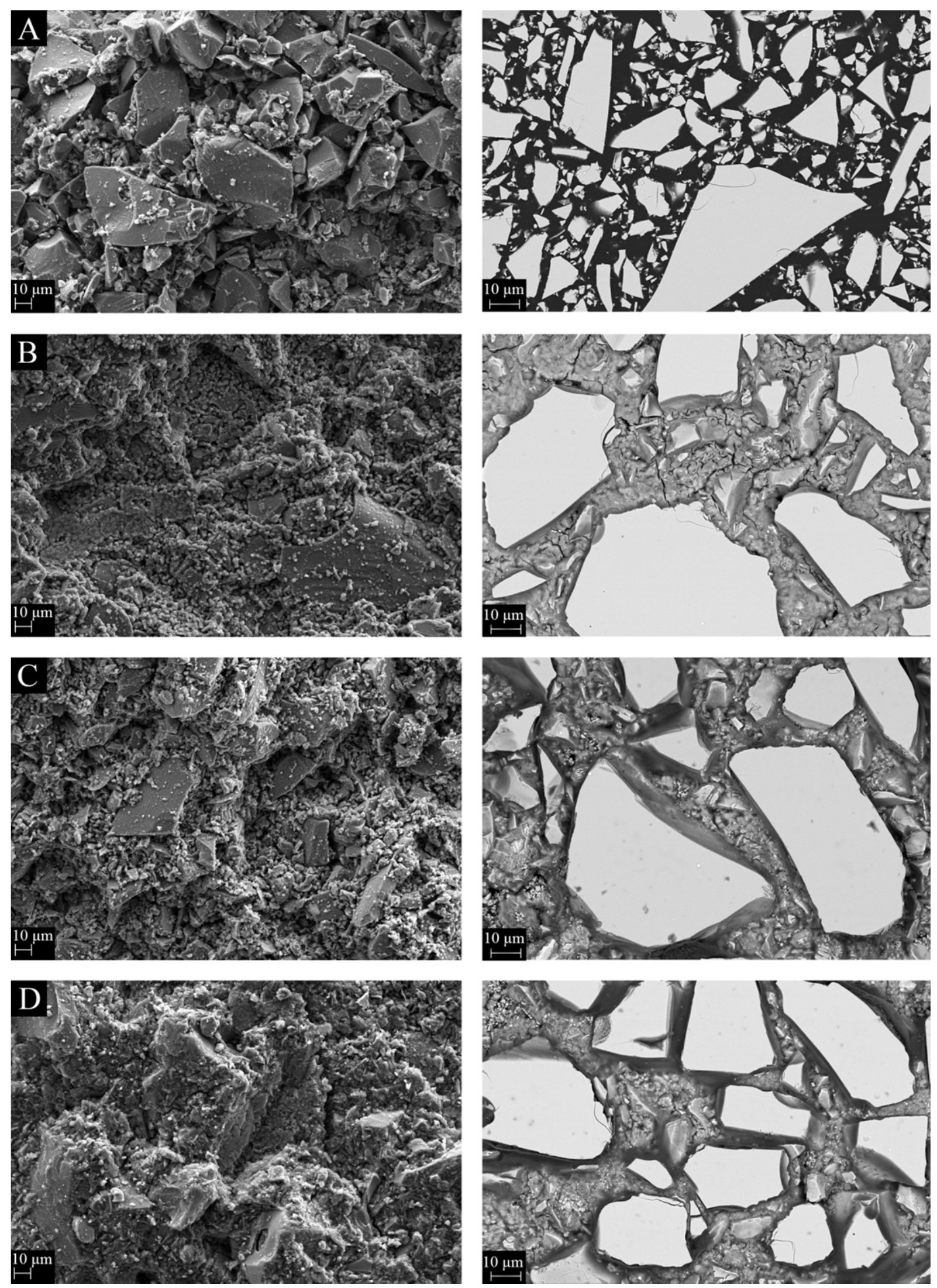

Fig. 7. SEM images of AAS pastes at 1 day. Left - SE image of fracture surface. Right - BSE image of polished surface: a) SC; b) SH50; c) OPC4; d) SFSL. 
Fig. 8 shows the microstructure of AAS pastes after 28 days of curing. All pastes showed solid continuous structure with only one exception, slag activated with sodium carbonate still had a friable and highly porous structure (Fig. 8A).
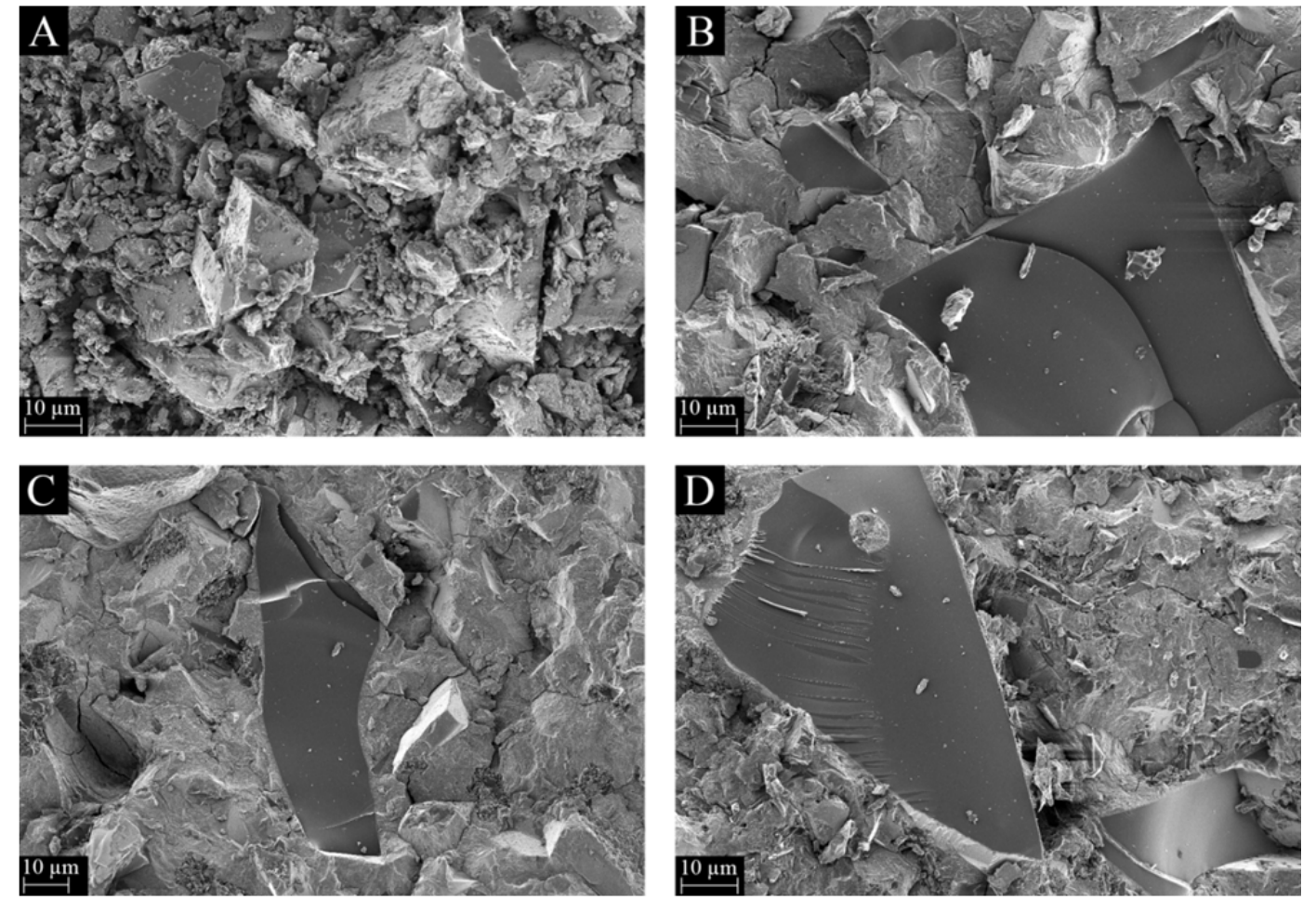

Fig. 8. SE images of fracture surface of AAS pastes at 28 days: a) SC; b) SH50; c) OPC4; d) SFSL.

Better resolution on sample topography at high magnification was achieved by the Ultra Plus Zeiss field emission microscope at low voltage (penetration depth of the electron beam into a sample is much less than at high voltages usually used in SEM investigations, and the sample is more stable at low voltage). Nanoscale images of the AAS pastes after 28 days of 
hardening are shown in Fig. 9. It can be seen that AAS pastes accelerated with OPC and the combination of silica fume and slaked lime, have highly tortuous structures on nanoscale (Fig. 9C,D) which correlates with tortuosity of microstructure of alkali-activated binders found by Provis et al [42]. The control (Fig. 9A) and accelerated with sodium hydroxide (Fig. 9B) AAS pastes do not have such structure. This pore network obstruction is most probably provided by riversideite $(\mathrm{C}-(\mathrm{A})-\mathrm{S}-\mathrm{H})$ because this type of $\mathrm{C}-\mathrm{S}-\mathrm{H}$ gel could be found only in the OPC4 and SFSL pastes (Fig. 9C,D) and the only difference as determined by XRD analysis, between these pastes and the rest of AAS pastes, was the formation of $\mathrm{C}-(\mathrm{A})-\mathrm{S}-\mathrm{H}$ gel which structure resembles riversideite.
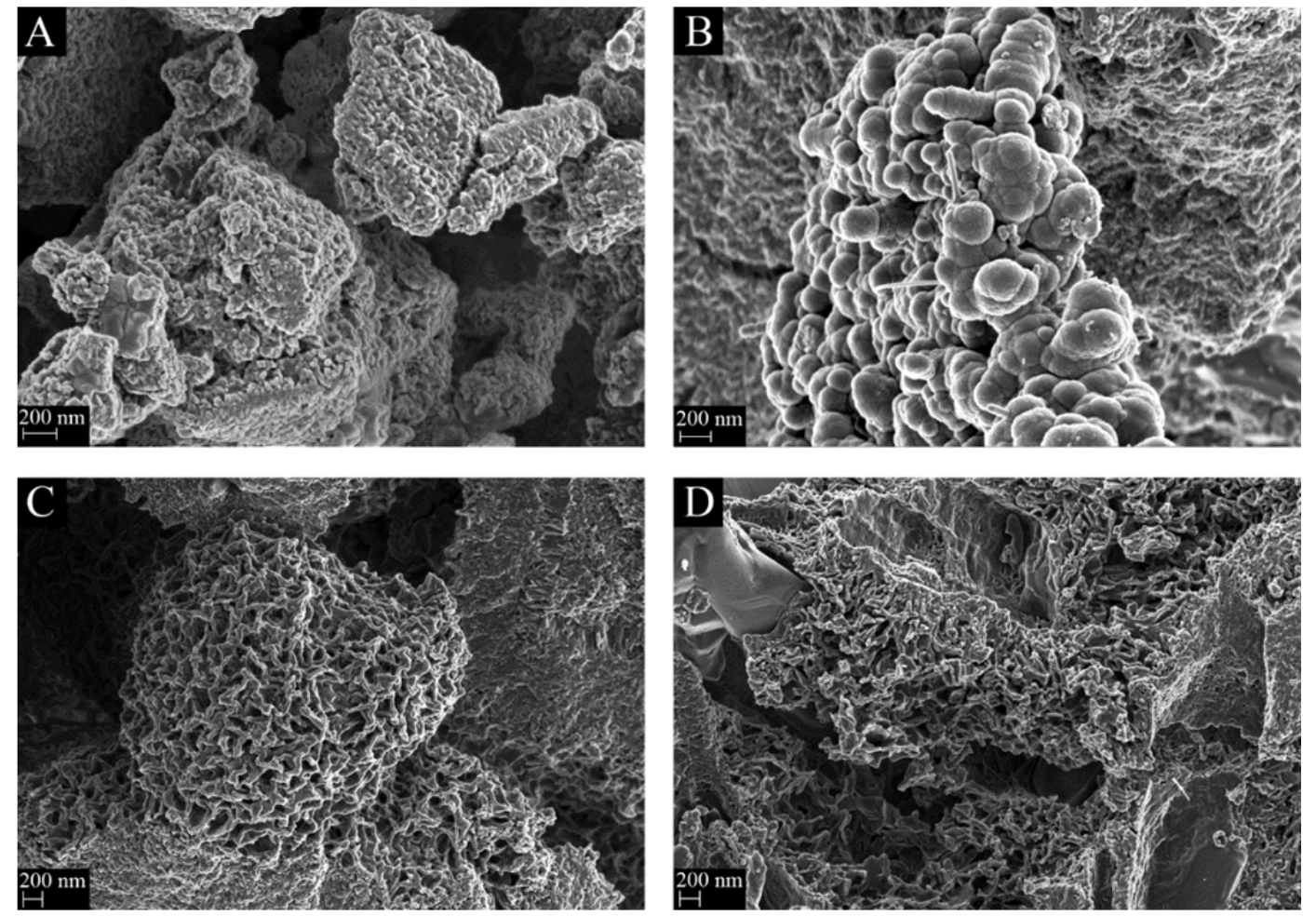

Fig. 9. Nanostructure of AAS pastes at 28 days: a) SC; b) SH50; c) OPC4; d) SFSL. 
Table 4 shows atomic ratios of hydration products calculated from X-ray microanalysis (EDS) data. It is important to note that these results could be affected by the sample surface roughness. Magnesium and part of aluminium can be assigned to the hydrotalcite which was found in some AAS pastes at 28 days by XRD analysis (Fig. 4). At early stage of hydration, discrete crystals of the hydrotalcite could not be detected by XRD analysis (Fig. 3) neither identified in the SEM images (Fig. 7,9), but previous studies of OPC-slag blended pastes by Richardson and Groves [43] found sub-micrometer sized crystals of this phase dispersed through C-S-H gel. X-ray microanalysis of AAS cement done by Wang and Scrivener [44] showed that $\mathrm{Mg} / \mathrm{Al}$ ratio of the hydrotalcite-type phase was 2.2 which is very close to $\mathrm{Mg} / \mathrm{Al}$ ratio of 2.0 of the hydrotalcite identified by XRD analysis (Fig. 4) in this study. According to Richardson and Groves [43], Al can replace the bridging $\mathrm{Si}$ in the dreierketten $\mathrm{C}-\mathrm{S}-\mathrm{H}$ structure. Assuming that pentrameric chains predominate in $\mathrm{C}-\mathrm{S}-\mathrm{H}$ structure, the presence of $\mathrm{Al}$ in all the bridging sites would result in an $\mathrm{Al} / \mathrm{Si}$ ratio of 0.25 [33]. Actual $\mathrm{Al} / \mathrm{Si}$ ratios found by Wang and Scrivener $[33,44]$ were in the range from 0.16 to 0.22 depending on activator used and age. Assuming that the hydrotalcite (Fig. 4) could form in all pastes at early age on sub-micrometer level, calculations based on its $\mathrm{Mg} / \mathrm{Al}$ ratio and EDS analysis results (Table 4) indicate that the rest of the aluminium contributes to $\mathrm{Al} / \mathrm{Si}$ ratios of 0.28 , $0.17,0.19$ and 0.25 for the control paste and pastes accelerated with sodium hydroxide, OPC, the combination of silica fume and slaked lime respectively. The $\mathrm{Al} / \mathrm{Si}$ ratios of the pastes accelerated with sodium hydroxide and OPC are in good correlation with the results of previous research $[33,44]$, but the control and accelerated with the combination of silica fume and slaked lime pastes have high $\mathrm{Al} / \mathrm{Si}$ ratios which according to Wang and Scrivener [44] is 
unlikely to be accommodated within the structure of the $\mathrm{C}-\mathrm{S}-\mathrm{H}$ gel at day 1 due to the insufficient degree of polymerization. The aluminium could be incorporated in AFm phase [44] but there is no clear evidence of its formation in XRD (Fig. 3,4) and ATR-FTIR (Fig. 5,6) analysis. ATR-FTIR results (Fig. 5) also supports the view that only part of Al in these pastes is in C-S-H gel structure; the peak about $960 \mathrm{~cm}^{-1}$ suggests that all AAS pastes have close $\mathrm{Al} / \mathrm{Si}$ ratios (higher $\mathrm{Al}$ uptake would shift the peak towards lower wave number $[37,38,41])$.

\section{Table 4}

Mean atomic ratios of AAS pastes at 1 day.

\begin{tabular}{lcccc}
\hline Paste & $\mathrm{Ca} / \mathrm{Si}$ & $\mathrm{Mg} / \mathrm{Si}$ & $\mathrm{Al} / \mathrm{Si}$ & $\mathrm{Na} / \mathrm{Ca}$ \\
\hline $\mathrm{SC}$ & $1.09 \pm 0.23$ & $0.74 \pm 0.10$ & $0.65 \pm 0.08$ & $0.13 \pm 0.04$ \\
$\mathrm{SH} 50$ & $1.29 \pm 0.33$ & $0.68 \pm 0.18$ & $0.51 \pm 0.14$ & $0.30 \pm 0.08$ \\
OPC4 & $1.05 \pm 0.22$ & $0.86 \pm 0.12$ & $0.62 \pm 0.03$ & $0.28 \pm 0.21$ \\
SFSL & $3.46 \pm 0.64$ & $0.21 \pm 0.04$ & $0.35 \pm 0.04$ & $0.48 \pm 0.24$
\end{tabular}

The $\mathrm{Ca} / \mathrm{Si}$ ratio for the paste accelerated with sodium hydroxide is higher than expected for tobermorite and this could be caused by intermixing with gaylussite and calcite which were identified by XRD (Fig. 3) and ATR-FTIR (Fig. 5) analysis. The paste accelerated with the combination of silica fume and slaked lime has the highest $\mathrm{Ca} / \mathrm{Si}$ ratio (Table 3) which should be caused by the addition of slaked lime and intermixing of $\mathrm{C}-(\mathrm{A})-\mathrm{S}-\mathrm{H}$ gel with carbonates (Fig. 3 and 5). The paste has prominent differences in the atomic ratios of hydration products 
in comparison to the rest of the AAS pastes. The content of $\mathrm{Mg}$ and $\mathrm{Al}$ is much lower, but the $\mathrm{Na}$ and $\mathrm{Ca}$ content is significantly higher. Significantly lower Mg and Al uptakes in the paste indicate that the hydration products at day 1 might be presented mostly by products of the reaction between the combined accelerator and the activator. Some of the slag has however participated in the reaction introducing $\mathrm{Mg}$ and $\mathrm{Al}$ into the hydration products.

\section{Conclusions}

AAS concretes containing neutral GBFS and activated with sodium carbonate can be accelerated by different admixtures which eliminates the necessity of heat treatment. Accelerating admixtures of sodium hydroxide, OPC and the combination of silica fume and slaked lime, influence the hydration products formed by AAS pastes. Calcium- and silica rich accelerators such as OPC and the combination of silica fume and slaked lime, promote the formation of $\mathrm{C}-(\mathrm{A})-\mathrm{S}-\mathrm{H}$ gel with a highly tortuous riversideite structure. In the case of AAS cement accelerated with OPC, riversideite only forms in the later stages, tobermorite like C(A)-S-H gel forms at early stages. AAS paste accelerated with the combination of silica fume and slaked lime contains only riversideite while paste accelerated with the addition of sodium hydroxide and the control non-accelerated AAS pastes produce only tobermorite. Thus, both types (riversideite and tobermorite) of $\mathrm{C}-(\mathrm{A})-\mathrm{S}-\mathrm{H}$ gel exist only in AAS paste accelerated with admixture of OPC, placing it as a transition between AAS pastes containing accelerating admixture of sodium hydroxide and the combination of silica fume and slaked lime. Sodiumcalcium carbonate, known as gaylussite, and calcite are identified in all AAS pastes indicating 
cation exchange reaction between the slag and the activator, as well as some degree of carbonation.

Further research is needed to investigate the causes of the relatively low long-term strength of AAS concretes accelerated with the combination of silica fume and slaked lime in comparison to the control non-accelerated AAS concrete containing neutral GBFS and sodium carbonate as activator.

\section{Acknowledgements}

The authors would like to thank Wiebke Grote and Jeanette Dykstra for their assistance in performing XRD and XRF analyses, Dr Salmon Lubbe for conducting the ICP-OES tests and Dr Robert Cromarty for his assistance in preparation of the polished samples. The efforts and assistance with SEM studies provided by André Botha and Antoinette Buys are gratefully acknowledged.

\section{References}

1. T. Bakharev, J.G. Sanjayan, Y.B. Cheng, Alkali activation of Australian slag cements, Cem. Concr. Res. 29 (1999) 113-120.

2. S.D. Wang, K.L. Scrivener, P.L. Pratt, Factors affecting the strength of alkali-activated slag, Cem. Concr. Res. 24 (6) (1994) 1033-1043. 
3. A. Fernandez-Jimenez, J.G. Palomo, F. Puertas, Alkali-activated slag mortars. Mechanical strength behaviour, Cem. Concr. Res. 29 (1999) 1313-1321.

4. C.D. Atiş, C. Bilim, Ö. Çelik, O. Karahan, Influence of activator on the strength and drying shrinkage of alkali-activated slag mortar, Constr. Build. Mater. 23 (2009) 548-555.

5. C. Shi, J.A. Stegemann, Acid corrosion resistance of different cementing materials, Cem. Concr. Res. 30 (2000) 803-808.

6. T. Bakharev, J.G. Sanjayan, Y.B. Cheng, Effect of elevated temperature curing on properties of alkali-activated slag concrete, Cem. Concr. Res. 29 (1999) 1619-1625.

7. S.D. Wang, X.C. Pu, K.L. Scrivener, P.L. Pratt, Alkali-activated slag cement and concrete: a review of properties and problems, Adv. Cem. Res. 7 (27) (1995) 93-102.

8. L.K. Turner, F.G. Collins, Carbon dioxide equivalent $\left(\mathrm{CO}_{2}-\mathrm{e}\right)$ emissions: A comparison between geopolymer and OPC cement concrete, Constr Build Mater 43 (2013) 125-130.

9. C. Shi, Strength, pore structure and permeability of alkali-activated slag mortars, Cem. Concr. Res. 26 (1996) 1789-1799.

10. M. Ben Haha, G. Le Saout, F. Winnefeld, B. Lothenbach, Influence of activator type on hydration kinetics, hydrate assemblage and microstructural development of alkali activated blast-furnace slags, Cem. Concr. Res. 41 (2011) 301-310.

11. A.J. Moseson, D.E. Moseson, M.W. Barsoum, High volume limestone alkali-activated cement developed by design of experiment, Cem. Concr. Compos. 34 (2012) 328-336.

12. H. Xu, J.L. Provis, J.S.J. van Deventer, P.V. Krivenko, Characterization of aged slag concretes, ACI Mater. J. 105 (2) (2008) 131-139.

13. F. Collins, J.G. Sanjayan, Early age strength and workability of slag pastes activated by $\mathrm{NaOH}$ and $\mathrm{Na}_{2} \mathrm{CO}_{3}$, Cem. Concr. Res. 28 (5) (1998) 655-664.

14. V.D. Glukhovsky, P.V. Krivenko, G.S. Rostovskaya, V.J. Timkovich, V.L. Pankratov, United States Patent No 4410365, 18 Oct 1983. 
15. S.A. Bernal, R.M. Gutierrez, A.L. Pedraza, J.L. Provis, E.D. Rodriguez, S. Delvasto, Effect of binder content on the performance of alkali-activated slag concretes, Cem. Concr. Res. 41 (2011) 1-8.

16. D. Ravikumar, S. Peethamparan, N. Neithalath, Structure and strength of $\mathrm{NaOH}$ activated concretes containing fly ash or GGBFS as the sole binder, Cem. Concr. Compos. 32 (2010) $399-410$.

17. British Standards Institution, BS EN 196-3:2005 Methods of testing cement - Part 3:

Determination of setting times and soundness, British Standards, UK, 2009.

18. M. Kovtun, E.P. Kearsley, J. Shekhovtsova, Dry powder alkali-activated slag cements, Adv. Cem. Res. http://dx.doi.org/10.1680/adcr.14.00078 (in press).

19. British Standards Institution, BS EN 12350:2009 Testing fresh concrete, British Standards, UK, 2009.

20. British Standards Institution, BS EN 12390-3:2009 Testing hardened concrete - Part 3: Compressive strength of test specimens, British Standards, UK, 2009.

21. R.S. Barneyback, S. Diamond, Expression and analysis of pore fluids from hardened cement pastes and mortars, Cem. Concr. Res. 11 (1981) 279-285.

22. T. Bakharev, J.G. Sanjayan, Y.B. Cheng, Effect of admixtures on properties of alkaliactivated slag concrete, Cem. Concr. Res. 30 (2000) 1367-1374.

23. V.D. Glukhovsky, P.V. Krivenko, V.N. Starchuk, I.A. Pashkov, V.V. Chirkova, Slagalkaline concretes produced from fine-grained aggregates, Vischa Shkola Publishing, Kiev, 1981 [in Russian].

24. I. Jawed, J. Skalny, Alkalies in cement: a review, Cem. Concr. Res. 8 (1978) 37-52.

25. M.H. Hubler, J.J. Thomas, H.M. Jennings, Influence of nucleation seeding on the hydration kinetics and compressive strength of alkali activated slag paste, Cem. Conc. Res. 41 (2011) 842-846. 
26. C. Shi, R.L. Day, A calorimetric study of early hydration of alkali-activated slag cements, Cem. Concr. Res. 25 (1995) 1333-1346.

27. C. Shi, R.L. Day, Some factors affecting early hydration of alkali-activated slag cements, Cem. Concr. Res. 26 (1996) 439-447.

28. E. Douglas, J. Brandstetr, A preliminary study on the alkali activation of ground granulated blast-furnace slag, Cem. Concr. Res. 20 (1990) 746-756.

29. A. Gruskovnjak, B. Lothenbach, L. Holzer, R. Figi, F. Winnefeld, Hydration of alkaliactivated slag: comparison with ordinary Portland cement, Adv. Cem. Res. 18 (3) (2006) $119-128$.

30. F. Poertas, A. Fernández-Jiménez, M.T. Blanco-Valera, Pore solution in alkali-activated slag cement pastes. Relation to the composition and structure of calcium silicate hydrate, Cem. Concr. Res. 34 (2004) 139-148.

31. S. Song, H.M. Jennings, Pore solution chemistry of alkali-activated ground granulated blast-furnace slag, Cem. Concr. Res. 29 (1999) 159-170.

32. I. Ismail, S.A. Bernal, J.L. Provis, S. Hamdan, J.S.J. van Deventer, Drying-induced changes in the structure of alkali-activated pastes, J. Mater. Sci. 48 (2013) 3566-3577.

33. S.D. Wang, K.L. Scrivener, ${ }^{29}$ Si and ${ }^{27}$ Al NMR study of alkali-activated slag, Cem. Concr. Res. 33 (2003) 769-774.

34. S.A. Bernal, J.L. Provis, D.G. Brice, A. Kilcullen, P. Duxson, J.S.J. van Deventer, Accelerated carbonation testing of alkali-activated binders significantly underestimate the real service life: the role of the pore solution, Cem. Concr. Res. 42 (10) (2012) 1317-1326. 35. I. García-Lodeiro, A. Fernández-Jiménez, A. Palomo, Hydration kinetics in hybrid binders: Early reaction stages, Cem. Concr. Compos. 39 (2013) 82-92.

36. V.C. Farmer, in: V.C. Farmer (Ed.), The infrared spectra of minerals, Mineralogical Society, London, 1974. 
37. P. Yu, R.J. Kirkpatrick, B. Poe, P.F. McMillan, X. Cong, Structure of Calcium Silicate Hydrate (C-S-H): Near-, Mid-, and Far-Infrared Spectroscopy, J. Am. Ceram. Soc. 82 (3) (1999) 742-748.

38. I. García-Lodeiro, A. Fernández-Jiménez, M.T. Blanco, A. Palomo, FTIR study of the sol-gel synthesis of cementitious gels: C-S-H and N-A-S-H, J. Sol-Gel Sci. Technol. 25 (2008) 63-72.

39. F. Puertas, M. Palacios, H. Manzano, J.S. Dolado, A. Rico, J. Rodríguez, A model for the C-A-S-H gel formed in alkali-activated slag cements, J. Euro. Ceram. Soc. 31 (2011) 20432056.

40. I. García-Lodeiro, D.E. Macphee, A. Palomo, A. Fernández-Jiménez, Effect of alkalis on fresh C-S-H gels. FTIR analysis, Cem. Concr. Res. 39 (2009) 147-153.

41. F. Puertas, A. Fernández-Jiménez, M.T. Blanco-Valera, Pore solution in alkali-activated slag cement pastes. Relation to the composition and structure of calcium silicate hydrate, Cem. Concr. Res. 34 (2004) 139-148.

42. J.L. Provis, R.J. Myers, C.E. White, V. Rose, J.S.J. van Deventer, X-ray microtomography shows pore structure and tortuosity in alkali-activated binders, Cem. Conc. Res. 42 (2012) 855-864.

43. I.G. Richardson, G.W. Groves, Microstructure and microanalysis of hardened cement pastes involving ground granulated blast-furnace slag, J. Mater. Sci. 27 (22) (1992) 62046212.

44. S.D. Wang, K.L. Scrivener, Hydration products of alkali activated slag cement, Cem. Concr. Res. 25 (3) (1995) 561-571. 